Johns Hopkins taking effect in the early spring, after which time she hopes to spend six months in Europe.

This professorship is undoubtedly the outgrowth of the interest in institutions and nurses which has been aroused at Columbia University through the course in Hospital Economics established there under the auspices of the Society of Superintendents of TrainingSchools for Nurses, and maintained by contributions from the nurses of the country. Miss Nutting's appointment is a direct recognition of the value of the work of nurses in institutions, and she is an especially able woman for the position. We extend to Miss Nutting our congratulations, in which we are sure the great nursing body joins us, in this opportunity for broader research work for the uplifting of her profession and for humanity at large.

\title{
THE RED CROSS
}

The headquarters of the National Red Cross Society in Washington had been moved to rooms adjoining the offices of the Medical Department of the army two days before the San Francisco disaster. The news of the earthquake was carried in to Miss Boardman by the Surgeon General of the army. The most perfect coopperation between the Red Cross and the Medical Department has been maintained since the day of the disaster, producing such results as had never been realized in any previous national calamity. Promptness and efficiency in reaching the state branches brought money, food and clothing in a marvelously short time, to be distributed under army supervision until such time as the San Francisco Red Cross, the Citizens' Committee and the army could form a working alliance. In the past the Red Cross and other philanthropic societies have worked in an attitude more of antagonism toward the government authorities. The re-organization of the Red Cross Society has brought about a wonderful reform in that respect, and the old condition that existed at so recent a date as the Spanish War can never return. The Red Cross stands in the fullest and broadest sense for the "brotherhood of man."

\section{NEW YORK STATE EXAMINATIONS}

ThE second of the full examinations in New York State will commence on June 19th and last four days. These examinations are held in New York, Albany, Syracuse and Buffalo. The practical 
test may be arranged for before this date in New York and Rochester by the superintendents of the training-schools conferring with the examiners located at these points. It is already known that there are to be 140 applicants in New York City alone, and it will simplify the work for the examination, as well as for the applicants, if the great majority of the practical tests can be taken at the points mentioned before the date fixed for the written examination.

Nurses who entered a registered training-school after April 27, 1903, who have finished their full term of training, and have been awarded their diplomas, are eligible for this examination. Those with time to make up or whose diplomas have not been awarded for any reason, will be obliged to hold over until the next examination in January. The great majority of the pupils graduating at this season entered their training just before April 27, 1903, and those can be registered under the waiver without examination.

\section{THE RELIEF OF SPECIAL-DUTY NURSES}

ARe nurses sufficiently relieved when on special duty in a hospital ? This is the question which is agitating the minds of a few Chicago physicians, and one of them suggests trying to get legislation to bear on the problem. Would legislation help us? Where and how do we fail?

Certainly there is a vast improvement in most of the Chicago hospitals over conditions which prevailed ten and fifteen years ago. Then, a nurse would be put on a hard surgical case and would be relieved only once or twice for rest; she would be relieved for class and lectures, almost always. Now, in most of the well-organized schools, a nurse is relieved the morning after an operation, for the whole day, to bathe, walk, and sleep, and is relieved for six hours out of the twenty-four thereafter until she can get a good amount of sleep at night. Most doctors, and most superintendents of nurses, think it is very hard on the patient to change the nurse during the first night after an operation. In two schools, however, the relieving is done almost entirely at night, and there is an extra night nurse on then, whose chief duty it is to relieve "specials," wherever she is most needed. In one leading school, the superintendent has all nurses who are on special duty send her a report in the morning, stating how much sleep they have had through the night, and she makes up to each one whatever amount is lacking of eight hours. 